\title{
Progress in the Application of Drugs for the Treatment of Multiple Sclerosis
}

\author{
Weipeng Wei ${ }^{1,2,3,4,5}$, Denglei Ma ${ }^{1,2,3,4,5}$, Lin $\mathrm{Li}^{1,2,3,4,5}$ and Lan Zhang ${ }^{1,2,3,4,5 *}$ \\ ${ }^{1}$ Department of Pharmacy, Xuanwu Hospital of Capital Medical University, Beijing, China, ${ }^{2}$ National Clinical Research Center for \\ Geriatric Diseases, Beijing, China, ${ }^{3}$ Beijing Engineering Research Center for Nervous System Drugs, Beijing, China, ${ }^{4}$ Beijing Institute \\ for Brain Disorders, Beijing, China, ${ }^{5}$ Key Laboratory for Neurodegenerative Diseases of Ministry of Education, Beijing, China
}

Multiple sclerosis (MS) is an autoimmune and chronic inflammatory demyelinating disease of the central nervous system (CNS), which gives rise to focal lesion in CNS and cause physical disorders. Although environmental factors and susceptibility genes are reported to play a role in the pathogenesis of MS, its etiology still remains unclear. At present, there is no complete cure, but there are drugs that decelerate the progression of MS. Traditional therapies are diseasemodifying drugs that control disease severity. MS drugs that are currently marketed mainly aim at the immune system; however, increasing attention is being paid to the development of new treatment strategies targeting the CNS. Further, the number of neuroprotective drugs is presently undergoing clinical trials and may prove useful for the improvement of neuronal function and survival. In this review, we have summarized the recent application of drugs used in MS treatment, mainly introducing new drugs with immunomodulatory, neuroprotective, or regenerative properties and their possible treatment strategies for MS. Additionally, we have presented Food and Drug Administration-approved MS treatment drugs and their administration methods, mechanisms of action, safety, and effectiveness, thereby evaluating their treatment efficacy.

Keywords: multiple sclerosis, autoimmune diseases, drug therapy, neurodegenerative, neuroprotective

\section{INTRODUCTION}

Multiple sclerosis (MS) is one of the malignant diseases that threaten the health of teenagers. Changes in environment and daily habits modulate the occurrence rate of this disease. MS is a chronic autoimmune disease of the central nervous system (CNS), which is characterized by demyelination and loss of nerve axons induced by an abnormal CNS-directed immune response and inflammation (Dendrou et al., 2015).

MS exhibits different phenotypes. In most patients, it is characterized by recurring clinical symptoms followed by complete or partial recovery, that is, typical relapsing-remitting MS (RRMS). After a period, the nervous system gradually deteriorates and a stage termed secondary progressive MS (SPMS) is established. However, some patients have accumulated disabilities caused by endless progression of the disease from the onset, which leads to primary progressive MS (PPMS) and clinically rare progressive relapsing MS (PRMS) (Gajofatto and Benedetti, 2015; Correale et al., 2017; De Angelis et al., 2018). The course of MS varies greatly among patients. Although significant progress has been made in the treatment in recent years, MS remains one of the most common causes of neurological dysfunction in young people. It mainly affects young and middle-aged individuals, with approximately $30 \mathrm{yr}$ as the peak age of onset, and the ratio of male to female patients is approximately 1 : 2. To date, the etiology and pathogenesis of MS have not been fully elucidated. Long onset time, multiple lesions, and wide spread are the clinical characteristics of MS, disseminating in time and space and greatly influencing function, economy, and quality of life. The cost of MS treatment is quite high and 
increases with an increase in disability. While current treatment options with different immunomodulatory or immunosuppressive effects mainly reduce the frequency and severity of recurrence, they cannot cure the disease (Klotz et al., 2019).

In recent years, based on the efforts of researchers and the study of MS drug therapy, new therapeutic drugs have been discovered and developed. MS is a complex disease and is classified as an organ-specific $\mathrm{T}$ cell-mediated autoimmune disease, its pathogenesis is not yet fully understood. Although several proven genetic elements have been described with regard to MS, many several environmental risk factors are shown to play an important role with the focus on vitamin D or ultraviolet B exposure, Epstein-Barr virus infection, obesity, or smoking (Dobson and Giovannoni, 2019; Teymoori-Rad et al., 2021). With increasing understanding of the pathogenesis of MS, it has been elucidated that environment factors, rather than genetic factors, play an important role in susceptibility. Furthermore, it is known that innate and adaptive immune systems and their effector cells, such as microglia, activated macrophages, and B and T lymphocytes, can influence the pathogenesis of MS (Oh et al., 2018; Yamout and Alroughani, 2018). This discovery not only revealed a new therapeutic target but also laid a foundation for the search of new therapeutic drugs. In this review, we aimed to summarize and discuss new findings in MS drug therapy, including drugs currently undergoing trials and those already approved by the Food and Drug Administration (FDA), focusing on latest reports and progress in drug treatment of diseases to provide a reference for further elucidating the pathogenesis and potential therapeutic targets of MS.

\section{Types and Characteristics of MS}

MS is the most common inflammatory disease of the CNS in young people. Its clinical symptoms vary, including sensory and visual impairment, limb weakness, tremor, limb movement disorder, visceral dysfunction, and mental depression. Lesions in MS correspond to local demyelination and inflammation, leading to glial reactions and eventual axonal injury. These lesions scatter throughout the CNS, including white and gray matter (Myhr, 2008; Bigaut et al., 2019). Traditionally, according to the characteristics of the clinical course, MS can be divided into four different clinical phenotypes: RRMS, SPMS, PPMS, and PRMS. According to the incidence and prognosis of MS, there are two rare clinical types of the disease, which overlap with the above clinical types, including benign and malignant MS. In benign MS, the number of relapses reduces within 10-15 yr after onset, while the nervous system still functions well. In contrast, patients with malignant MS exhibit sudden onset of the disease, which progresses rapidly with subsequent neurological deterioration, resulting in disability or death.

\section{Relapsing Remitting Multiple Sclerosis, RRMS}

RRMS has a remission cycle of relapse and remission, which is characterized by acute remission (relapse) and relatively stable intermission (remission). In this phenotype, a patient recovers after each attack, leaving no or only mild sequelae. The condition of the two relapse intervals is stable and has the best response to treatment, and up to half of the patients with RRMS may exhibit the secondary progressive type of MS after a period. The incidence rate of RRMS among women is approximately twice that among men, and approximately $85-90 \%$ of patients with MS present this phenotype. Its pathogenesis is the production of lumpy demyelinating areas of varying sizes in the neurocellulose area, and its pathological characteristics are varying degrees of inflammatory cell infiltration, demyelination, axonal injury, and astrocyte hyperplasia. RRMS is the most common type of MS and the hot spot of clinical research.

\section{Secondary Progressive Multiple Sclerosis, SPMS}

After 10-15 years of illness, approximately $50 \%$ of RRMS patients no longer experience relapse and remission, and show slow progressive aggravation, which manifests as a stage of continuous deterioration of disability with or without seizures.

\section{Primary Progressive Multiple Sclerosis, PPMS}

PPMS is rare and onset occurs in a relatively older age, accounting for approximately $10 \%$ of MS occurrence. The disease has a course duration of $1 \mathrm{yr}$ or more; it progresses slowly showing only short-term, insignificant symptom improvement with no remission or recurrence and exhibits poor response to treatment.

\section{Progressive Relapsing Multiple Sclerosis, PRMS}

PRMS is clinically rare and is characterized by gradual development and aggravation, occasional recurrence, and continuous progression between two relapses.

\section{Application of Drugs for the Treatment of MS}

\section{Drugs Approved by FDA}

The treatment of MS is mainly based on the use of immunosuppressants and immunomodulators. Until 1993, MS treatment was not licensed; however, several treatments are now available (Ziemssen, 2011; Antonio Garcia Merino, 2014; Boster et al., 2017; Kidd et al., 2017). Currently, approved drugs for the treatment of MS are usually disease modifiers, which only reduce the incidence of the disease and delay its progression in some patients. It is believed that these treatments are only effective against the inflammatory component of the disease (Bagherpour et al., 2018). With rapid progress in the development of effective MS therapeutic drugs, a variety of these drugs are now marketed. Although many drugs are used to treat MS in the clinic, only a few of them have been approved by the FDA. At present, the products approved by the FDA for the treatment of MS include interferon (IFN)- $\beta$, glatiramer acetate (GA), teriflunomide, fingolimod 
TABLE 1 | List of drugs approved by the FDA for the treatment of MS.

\begin{tabular}{lc}
\hline Product name & \multicolumn{1}{c}{$\begin{array}{c}\text { Dosage and } \\
\text { Administration }\end{array}$} \\
\hline $\begin{array}{l}\text { IFN- } \beta \text {-1b (Betaseron) Yu etal. } \\
\text { (2015) }\end{array}$ & $250 \mu \mathrm{g}$ i.H. every 2 days
\end{tabular}

(2015)
Pharmacological actions and Mechanisms

Activates the JAK/STAT pathway connected by IFN receptor, resulting in transcriptional changes in immune and anti-proliferative genes, and reduces the migration of lymphocytes across the BBB
IFN- $\beta$-1a (Avonex) Pavelek $30 \mu \mathrm{g}$ i.m. once a week et al. (2020)
Inhibits the proliferation of MBP-specific T cells and their penetrating migration to the BBB, reduces the production of pro-inflammatory factors, and induces the increase of antiinflammatory factors

\section{Adverse reactions}

Approved

Influenza-like syndrome, skin reaction at injection site, headache, leukopenia, etc.

\section{Competitively binds $\mathrm{MHC}$ I and II molecules of} APC to block MBP specific T cell receptor, inhibits $T$ cell proliferation, down-regulates the secretion of inflammatory cytokines, and upregulates the production of brain-derived neurotrophic factor

$\begin{array}{ll}\text { Mitoxantrone Edan et al. } & \text { 4-12 mg i.v.gtt } \\ \text { (2004); Burns et al. (2012) } & \text { every } 3 \text { mo }\end{array}$

Embeds into DNA base molecules to inhibit DNA synthesis, inhibits the presentation of antigens for $T$ and $B$ cells, reduces the secretion of proinflammatory cytokines, such as TNF- $\alpha$, and enhances anti-inflammatory response

IFN- $\beta$-1a (Rebif) Hupperts $\quad 44 \mu \mathrm{g}$ i.H. every 3 wk et al. (2019)

Promotes the balance of Th1 and Th2 cells, reduces the secretion of proinflammatory cytokines, enhances the expression of inhibitory cytokines, and reduces the entry of T cells into the CNS through the BBB

Natalizumab Zhovtis Ryerson 300 mg i.v. every 4 wk et al. (2020)

Anti- $\alpha 4$ integrin monoclonal antibody; binds and blocks the interaction between a4 integrin and ligand and prevents lymphocytes from entering the CNS through the BBB

Fingolimod Imeri et al. (2021) $500 \mu$ g p.o. once a day S1P receptor modulator; protects and repairs neurons through the BBB and prevents central memory $T$ cell subsets from migrating to the CNS

$\begin{array}{ll}\text { Teriflunomide Buron et al. } & 7 \text { or } 14 \mathrm{mg} \text { p.o. once } \\ \text { (2021) } & \text { a day }\end{array}$

Dihydroorotate dehydrogenase inhibitor; reduces DNA synthesis, inhibits $T$ and $B$ cell proliferation and production of cytokines, and inhibits intercellular adhesion molecule production

Tecfidera Naismith et al. (2020a); Naismith et al. (2020b)

Alemtuzumab Gross et al. (2016); Paterka et al. (2016)

12 mg i.v. once a day

Peginterferon beta-1a Menge $125 \mu \mathrm{I}$ I.H. every 2 wk et al. (2021)

Daclizumab Cohan (2016); Gold et al. (2016)

240 mg p.o. twice a day Regulates the levels of Nrf2 and glutathione in $\mathrm{T}$ cells, activates antioxidant genes, and promotes the transformation of Th1 to Th2

CD52 monoclonal antibody; induces the clearance of $\mathrm{T}$ and $\mathrm{B}$ cells and increases the secretion of brain-derived neurotrophic factor

Reduces the expression of adhesion molecules on the surface of $T$ cells, inhibits the activation of $\mathrm{T}$ cells, and reduces the infiltration of the CNS

CD25 monoclonal antibody; inhibits IL-2 receptor signal transduction and $\mathrm{T}$ cell activation and proliferation
Influenza-like syndrome, anemia, fever, myalgia, weakness, etc.

Skin reaction at the injection site, palpitations, dyspnea, chest pain, vasodilation, etc.

Intestinal reactions, alopecia, peripheral blood 2000 leukopenia, abnormal liver function, etc.

Influenza-like syndrome, skin reaction at the 2003 injection site, myalgia, abdominal pain,

elevated liver enzymes, etc.

Headache, urinary tract infections, abdominal

2004 pain, fatigue, joint pain, gastroenteritis, etc.

Systemic virus infection, headache, influenza, gastrointestinal discomfort, abnormal liver function, angina pectoris

Dyspnea, renal failure, hypertension, 2012 leukopenia, alopecia, etc.

Abdominal pain, diarrhea, nausea, skin itching,

2013 rash, erythema, etc.

Rash, headache, fever, other autoimmune 2014 diseases, etc.

Influenza-like symptoms, injection site reaction, 2014 and deterioration of depression

Severe infections and skin reactions, abnormal 2016 liver function, etc. 
TABLE 1 | (Continued) List of drugs approved by the FDA for the treatment of MS.

\begin{tabular}{|c|c|c|c|c|}
\hline Product name & $\begin{array}{l}\text { Dosage and } \\
\text { Administration }\end{array}$ & Pharmacological actions and Mechanisms & Adverse reactions & Approved \\
\hline $\begin{array}{l}\text { Ocrelizumab Patel et al. } \\
\text { (2021) }\end{array}$ & 300 mg i.v. every 2 wk & $\begin{array}{l}\text { Monoclonal antibodies against CD20 on } \\
\text { immature and mature B cells; removes CD20 } \\
\text { positive B cells using CDC and ADCC }\end{array}$ & $\begin{array}{l}\text { Skin reaction at the injection site, headache, } \\
\text { malignant tumor, etc. }\end{array}$ & 2017 \\
\hline $\begin{array}{l}\text { Cladribine Miravalle et al. } \\
\text { (2021) }\end{array}$ & $\begin{array}{l}10 \mathrm{mg} \text { p.o. }(3.5 \mathrm{mg} / \mathrm{kg} \\
\text { cumulative dose } \\
\text { over } 2 \mathrm{yr})\end{array}$ & $\begin{array}{l}\text { Nucleoside analogue; inhibits DNA synthesis } \\
\text { and DNA chain termination and cytotoxic to } \\
\text { lymphocytes and monocytes }\end{array}$ & $\begin{array}{l}\text { Respiratory tract infection, headache, } \\
\text { lymphocytopenia, etc. }\end{array}$ & 2019 \\
\hline $\begin{array}{l}\text { Siponimod Spampinato et al. } \\
(2021)\end{array}$ & $\begin{array}{l}250 \mu g \text { or } 2 \text { mg p.o. once } \\
\text { a day }\end{array}$ & $\begin{array}{l}\text { S1P-1 receptor modulator; enters the brain and } \\
\text { CNS of MS patients through the BBB, binds to } \\
\text { S1P receptor, promotes myelin regeneration, } \\
\text { prevents activation of harmful cells, delays } \\
\text { disability progression, and preserves cognitive } \\
\text { function }\end{array}$ & $\begin{array}{l}\text { Increased blood pressure, decreased heart } \\
\text { rate, delayed atrioventricular conduction, } \\
\text { macular edema, respiratory and skin } \\
\text { infections, etc. }\end{array}$ & 2019 \\
\hline $\begin{array}{l}\text { Ozanimod Lamb (2020); US } \\
\text { Food and Drug } \\
\text { Administration (2020) }\end{array}$ & $250 \mu \mathrm{g}$ p.o. once a day & $\begin{array}{l}\text { A novel S1P and dual subtypes of S1P1 and } \\
\text { S1P5 receptor modulators; enters the brain and } \\
\text { CNS through the BBB and binds to S1P } \\
\text { receptors to promote myelin regeneration, } \\
\text { prevents activation of harmful cells, delays } \\
\text { disability progression, and preserves cognitive } \\
\text { function in patients }\end{array}$ & $\begin{array}{l}\text { Respiratory tract infection, urinary tract } \\
\text { infection, transient decrease of heart rate and } \\
\text { delayed atrioventricular conduction, elevated } \\
\text { blood pressure, etc. }\end{array}$ & 2020 \\
\hline
\end{tabular}

i.H., subcutaneous injection; i.m., intramuscular injection; i.v. gtt, intravenous drop infusion; i.v., intravenous injection; p.o., per os; IFN, interferon; BBB, blood-brain barrier; MBP, myelinbasic protein; MHC, major histocompatibility complex; APC, antigen-presenting cells; TNF, tumor necrosis factor; Th, helper T cells; CNS, central nervous system; S1P, sphingosine-1phosphate; Nrf2, nuclear factor erythroid 2-related factor 2; IL, interleukin; CD, cluster of differentiation; CDC, complement-dependent cytotoxicity; ADCC, antibody dependent cellular cytotoxicity.

(FTY), mitoxantrone, natalizumab, dimethyl fumarate, and alemtuzumab (Table 1).

\section{Interferon (IFN)}

IFN was the first cytokine discovered and studied in humans. It can activate macrophages, increase natural killer cell activity, and inhibit virus replication; it was originally used in antiviral therapy. IFN can be divided into three types according to their origin and structure: $\alpha, \beta$, and $\gamma$. IFN- $\beta$ is effective, IFN- $\alpha$ is ineffective, and IFN- $\gamma$ can aggravate the disease (Wittling et al., 2020; Shen et al., 2021). IFN- $\beta$ has been recommended as a firstline drug for patients with RRMS by the FDA. The mechanism of action of IFN- $\beta$ involves the inhibition of lymphocyte proliferation and antigen expression, regulation of antiinflammatory phenotypic cytokinesis products in the circulatory system and CNS, inhibition of $\mathrm{T}$ cell matrix metalloproteinase activity, and reduction of inflammatory T cell migration (Shahi et al., 2020).

The first generation of IFN- $\beta$ was approved by the FDA in 1993 and is the earliest disease-modifying treatment used for MS. Two kinds of IFN- $\beta$ compounds exist, IFN- $\beta-1 \mathrm{a}$ and IFN- $\beta-1 \mathrm{~b}$, both of which must be injected (Zettl et al., 2018). IFN is a small protein that can be degraded or cleared quickly; thus, it is administered frequently, ranging from every other day to once a week (Jain and Jain, 2008). Currently, three parenteral IFN- $\beta$ preparations are approved for the treatment of MS: IFN- $\beta-1 \mathrm{~b}$ is subcutaneously injected every other day, IFN- $\beta-1 \mathrm{a}$ is subcutaneously injected three times a week, and IFN- $\beta$-1a is injected intramuscularly once a week. IFN- $\beta$ is an immunomodulatory drug with multiple targets; however, its exact mode of action is not yet completely clear (Filippini et al., 2017). The therapeutic effect of IFN- $\beta$ has been determined, and its greatest advantage is that it has no deleterious side effects, such as malignant tumors or teratogenicity (Rommer and Zettl, 2018). Its limitations include side effects, such as skin reactions (from erythema and itching to infection and even necrosis), influenza symptoms, muscle pain, joint pain, chills, headache, and body weakness. Therefore, injection-related adverse events can negatively influence compliance, and the need for frequent administration may become an obstacle to MS treatment (Mohr et al., 2001; Patti, 2010; Beer et al., 2011; Menzin et al., 2013).

\section{Glatiramer Acetate (GA)}

GA, approved by the FDA in 1996, is an immunomodulating amino acid copolymer (Aharoni, 2013). Its mechanism of action involves the activation of $\mathrm{T}$ cells and induction of Th2 cell production. Th2 cells can promote the production of antiinflammatory cytokines, such as interleukin (IL)-4, IL-10, and TGF- $\beta$, thus playing an immunomodulatory role. Commonly, a dose of $20 \mathrm{mg}$ once a day is administered subcutaneously. At present, no additional benefit of a higher GA dose has been found, and the effect of the drug on the recurrence rate of MS after $2 \mathrm{yr}$ of treatment is similar to that of IFN- $\beta$ (Comi et al., 2011; La Mantia et al., 2015; van Dijkman et al., 2018). Although GA is safe, some patients still experience adverse reactions. Skin reaction at the site of injection is frequent, and fat atrophy may occur. Injection-related 
reactions include blushing, chest pain, palpitations, urticaria, and dyspnea; these side effects and the need for daily injection lead to a huge burden, which negatively influences treatment sustainability (Patti, 2010; Beer et al., 2011; Krysko et al., 2020).

\section{Teriflunomide}

Teriflunomide is an inhibitor of pyrimidine synthase (dihydroorotate dehydrogenase). It plays a neuroprotective role by inhibiting dihydroorotate dehydrogenase, blocking the synthesis of DNA and RNA, and reducing the proliferation of immune cells (Bar-Or et al., 2014). Teriflunomide is a daily oral disease modification therapy approved for the treatment or relief of recurrent MS. This compound is the main active metabolite of leflunomide, a drug approved for the treatment of rheumatoid arthritis. Teriflunomide selectively and reversibly inhibits dihydrophosphate dehydrogenase, which is the key mitochondrial enzyme for deoxypyrimidine synthesis required for the rapid division of $\mathrm{B}$ and $\mathrm{T}$ lymphocytes. Through this cellular static effect, teriflunomide has the potential to limit the immune response that leads to MS activity (Gold and Wolinsky, 2011; Confavreux et al., 2014). Related studies have shown that $14 \mathrm{mg}$ of the drug can significantly reduce the annual recurrence rate of MS per patient and the risk of disability progression lasting at least $12 \mathrm{wk}$. Further, it has been reported that $7 \mathrm{mg}$ of teriflunomide can significantly reduce the annual recurrence rate of MS; however, this dose has no significant effect on disability progression. In addition, extended studies have shown that long-term (approximately $8.5 \mathrm{yr}$ ) treatment with teriflunomide can maintain the efficacy of drug. Diarrhea, nausea, thinning of hair (alopecia), and increased concentration of alanine aminotransferase are the most common adverse reactions associated with teriflunomide (O'Connor et al., 2011; Confavreux et al., 2012; Wolinsky et al., 2013; Confavreux et al., 2014).

\section{Fingolimod (FTY)}

FTY, the first oral immunosuppressant and a sphingosine-1phosphate receptor (S1PR) modulator, was approved by the FDA in 2010 as an oral drug for the treatment of MS. The main mechanism of action is to inhibit the release of lymphocytes from the peripheral lymphoid tissue by binding to S1PR on the surface of lymphocytes after phosphorylation or to induce lymphocytes in peripheral blood to migrate back to the peripheral lymphoid tissue and reduce their entry into the CNS. In addition, FTY can directly regulate the expression of S1PR on the surface of oligodendrocytes and neurons through the blood-brain barrier (BBB), and plays a role in neuroprotection and repair. Five different types of S1PRs exist, among which FTY binds to S1PR 1, 3, 4, and 5, and the immunomodulatory effect of FTY may be mediated by S1PR1. The internalization of the receptor makes it impossible for immune cells to leave the lymphoid tissue or enter the CNS to promote an autoimmune response. The results of clinical trials show that FTY is effective in patients with recurrent MS, and oral administration can reduce the treatment burden of the injection (Cohen et al., 2016; Matko et al., 2020).
The related side effects of FTY in the trial included cardiac autonomic nervous dysfunction, high infection rates (especially herpes infection), melanoma, and eye problems associated with the development of macular edema. Additionally, animal studies have reported teratogenicity and embryonic lethality, including organ defects, especially permanent truncus arteriosus and ventricular septal defects (Cohen et al., 2010; Findling et al., 2020).

\section{Mitoxantrone}

Mitoxantrone, an immunosuppressant, is a topoisomerase II inhibitor that inhibits cellular DNA replication, transcription, and repair. It was originally used to treat diseases, such as myeloid leukemia and prostate cancer. In 2000, mitoxantrone was approved by the FDA for the treatment of patients with worsening RRMS and SPMS, and its effect on the treatment of RRMS was definite. Mitoxantrone is similar to an embedding agent in the treatment of MS when it is embedded in DNA base molecules, which inhibits DNA synthesis and the presentation of antigens, such as $\mathrm{T}$ and $\mathrm{B}$ cells, reduces the secretion of inflammatory cytokines, such as tumor necrosis factor (TNF), and plays an immunosuppressive and neuroprotective role (Jeffery and Herndon, 2004; Martinelli et al., 2009). The drug is administered once every 3 mo for $2 \mathrm{yr}$, which can reduce the recurrence frequency, lesion formation, and disability rate associated with MS. However, the clinical application of mitoxantrone is limited because of its side effects, including cardiotoxicity, hair loss, constipation, and abnormal liver function.

\section{Potential New Drugs for MS}

MS is a complex inflammatory autoimmune disease of unknown etiology. It is believed that the pathogenesis of MS mainly occurs as an immune response to myelin or myelin-forming cells (oligodendrocytes) owing to the presence of abnormally activated $\mathrm{T}$ cells in the CNS, which leads to progressive demyelination in the CNS and neurodegenerative diseases. Macrophages, self-reactive $\mathrm{CD} 8^{+} \mathrm{T}$ cells, Th1 and Th17 cells, and clonal expanded $\mathrm{B}$ cells have been reported to dominate the inflammatory infiltration of the BBB. Further, a number of autoantibodies and autoreactive $\mathrm{T}$ cells have been found in patients with MS (Bittner et al., 2014; Lombardo et al., 2019). Inflammatory cytokines produced by self-reactive $\mathrm{T}$ cells passing through the BBB and the CNS can cause damage to myelin and surrounding tissues, and microglia and astrocytes in the CNS are activated during inflammation and produce pro-inflammatory mediators that worsen the disease (Dendrou et al., 2015). The classification of MS is also an important reference for the choice of therapeutic drugs. It is suggested that we should combine the typing of MS with the factors affecting the CNS and the corresponding types of immune cells to study whether different influencing factors act on different parts of the nervous system, resulting in different types of MS in order to further study the pathogenesis of MS and find a new target for MS therapy. Therefore, based on the above, we focus on adaptive immune responses in T and B cells, as well as myeloid cells of the innate immune system (dendritic cells (DCs), astrocytes, microglia, and oligodendrocytes), to discuss the role of drugs 
TABLE 2 | Drugs undergoing phase || and III clinical trials for the treatment of MS.

\begin{tabular}{|c|c|c|c|}
\hline Product name & $\begin{array}{l}\text { Clinical trials } \\
\text { (Phase) }\end{array}$ & Pharmacological actions and Mechanisms & References \\
\hline Rituximab & III & CD20 monoclonal antibody; promotes the rapid extinction of B cells & $\begin{array}{l}\text { Zhong et al. (2020); Chisari et al. } \\
\text { (2021) }\end{array}$ \\
\hline Laquinimod & III & $\begin{array}{l}\text { Regulates pro-inflammatory or anti-inflammatory cytokines secretion by Th1 and Th2 cells, } \\
\text { and increase of brain-derived neurotrophic factor }\end{array}$ & $\begin{array}{l}\text { Jolivel et al. (2013); Luhder et al. } \\
\text { (2017) }\end{array}$ \\
\hline Ipilimumab & II & $\begin{array}{l}\text { Monoclonal antibody; effectively blocks the molecule of CTLA-4 and humanized antibody } \\
\text { targeting cytokine LINGO-1 }\end{array}$ & Gerdes et al. (2016) \\
\hline Ibudilast & II & $\begin{array}{l}\text { Non-selective phosphodiesterase inhibitor; inhibits pro-inflammatory cytokines, promotes } \\
\text { neurotrophic factors, and weakens activated glial cells }\end{array}$ & $\begin{array}{l}\text { Fox et al. (2018); Naismith et al. } \\
\text { (2021) }\end{array}$ \\
\hline $\begin{array}{l}\text { Epigallocatechin-3- } \\
\text { gallate }\end{array}$ & II & $\begin{array}{l}\text { Inhibits brain inflammation, neuronal injury, T cell proliferation, and TNF-a secretion in } \\
\text { encephalitis }\end{array}$ & Spagnuolo et al. (2018) \\
\hline Cannabinoids & II & $\begin{array}{l}\text { Cannabis receptor agonist; regulates the activation of cannabis receptors, resulting in a } \\
\text { significant reduction of inflammatory cytokines and promoting the induction of anti- } \\
\text { inflammatory cytokines }\end{array}$ & Al-Ghezi et al. (2019) \\
\hline Erythropoietin & II & $\begin{array}{l}\text { Reduces the secretion of pro-inflammatory factors, maintains the integrity of the BBB, and } \\
\text { increases the number of brain-derived neurotrophic factor positive cells and } \\
\text { oligodendrocytes }\end{array}$ & $\begin{array}{l}\text { Moransard et al. (2017); Gyetvai } \\
\text { et al. (2018) }\end{array}$ \\
\hline Flupirtine & II & $\begin{array}{l}\text { Activates inward rectifier potassium channels, plays a neuroprotective role and up-regulates } \\
\text { Bcl-2 to increase neuronal survival }\end{array}$ & Shirani et al. (2016) \\
\hline Oxcarbazepine & II & A neuroprotective agent; inhibits microglial activity and neuronal sodium load & Cunniffe et al. (2021) \\
\hline
\end{tabular}

CD, cluster of differentiation; Th, helper T cells; MHC, major histocompatibility complex; CTLA-4, cytotoxic T cell antigen-4; LINGO-1, leucine-rich repeat and immunoglobulin domaincontaining protein 1; TNF, tumor necrosis factor; BBB, blood-brain barrier; Rho, IL, interleukin.

in the treatment of patients with MS and some animal models with the aim of finding new targets and strategies for the development of therapeutic drugs for MS.

Although several therapeutic drugs for MS are available in the clinic, immunomodulatory drugs to control the recurrence of MS or completely cure the disease are not enough and the treatment cost is quite high. However, because of deleterious side effects, adverse reactions caused by cyclophosphamide in the treatment of MS cannot be ignored; for example, cyclophosphamide in the treatment of MS often causes adverse reactions, such as peripheral leukopenia, gastrointestinal reactions, hemorrhagic cystitis, malignant tumors, and increased infertility. Thus, it is not used clinically (La Mantia et al., 2007; Patti and Lo Fermo, 2011; Findling and Sellner, 2021). Glucocorticoid drugs, such as methylprednisolone, are mainly used for the treatment of acute
MS (Sato et al., 2012). Therefore, the need to develop new drugs and approaches for the treatment of MS persists. In recent years, with the in-depth study of MS, researchers have explored the mechanism of the immune system in inflammatory demyelination, neuronal injury, and myelin regeneration as well as the association between the immune system and CNS to find a better and more effective treatment strategy for MS. At present, research on MS therapeutic drugs is developing rapidly, and a number of these drugs are undergoing phase II and III clinical trials (Table 2) and basic study (Table 3).

\section{MS Drugs Acting on dendritic cells (DCs)}

DCs are full-time antigen-presenting cells that do not only efficiently absorb, process, and present antigens as well as mediate antigen-specific immune responses but also regulate 
TABLE 3 | Drugs that are being studied for the treatment of MS in recent years.

\begin{tabular}{|c|c|c|c|}
\hline Drugs name & $\begin{array}{l}\text { Animal } \\
\text { model }\end{array}$ & Pharmacological actions and Mechanisms & References \\
\hline Rapamycin & EAE & Inhibits the activation of Th1 cells and superfunction of Th17 cells & Li et al. (2020) \\
\hline Tacrolimus, FK506 & EAE & $\begin{array}{l}\text { Inhibits the dephosphorylation of nuclear factors in active } T \text { lymphocytes, reduces the } \\
\text { secretion of IL-2, and inhibits the proliferation and activation of } T \text { cells }\end{array}$ & Kim et al. (2017) \\
\hline Methylprednisolone & EAE & $\begin{array}{l}\text { Regulates the gene expression of } \mathrm{CD} 4^{+} \mathrm{T} \text { lymphocytes, induces the proliferation of Treg } \\
\text { cells, and reduces the secretion of proinflammatory cytokines }\end{array}$ & De Andres et al. (2018) \\
\hline Metformin & CPZ & $\begin{array}{l}\text { Activates AMPK pathway, induces oligodendrocyte and myelin proliferation, and } \\
\text { reduces the proliferation of astrocytes and microglia }\end{array}$ & Largani et al. (2019) \\
\hline Aspirin & EAE & $\begin{array}{l}\text { Increases the level of IL-11, up-regulates Treg cells, and decreases Th1 and Th17 cells } \\
\text { response }\end{array}$ & Pahan and Pahan (2019) \\
\hline Trichostatin A & EAE & $\begin{array}{l}\text { Histone deacetylase inhibitor; promotes the induction of peripheral T cell tolerance, } \\
\text { reduces the migration of T cells to the spinal cord, and reduces neuronal injury }\end{array}$ & Jayaraman et al. (2017) \\
\hline Ruxolitinib & EAE & $\begin{array}{l}\text { Decreases the proportion of Th17 cells and the level of inflammatory factors, and } \\
\text { increases the balance of Tregs and level of anti-inflammatory cytokines }\end{array}$ & Hosseini et al. (2021) \\
\hline Tofacitinib & EAE & $\begin{array}{l}\text { Inhibits DCs expression of costimulatory molecules, activates marker molecules and } \\
\text { pro-inflammatory factors, inhibits antigen-specific T cell activation and differentiation, } \\
\text { and reduces spinal cord leukocyte infiltration }\end{array}$ & Zhou et al. (2016) \\
\hline Hydroxyfasudil & $\mathrm{CPZ}$ & $\begin{array}{l}\text { Reduces microglial-mediated neuroinflammation and promotes the production of } \\
\text { astrocyte-derived BDNF and the regeneration of NG2 oligodendrocyte precursor cells }\end{array}$ & Wang et al. (2019) \\
\hline a-lipoic acid & EAE & $\begin{array}{l}\text { Inhibits the proliferation of T lymphocytes and macrophages in the CNS and reduces } \\
\text { axonal injury }\end{array}$ & Baldassari and Fox (2018) \\
\hline Cornus iridoid glycoside & EAE & $\begin{array}{l}\text { Limits the entry of T cells into the CNS and the activation of microglia, increases the } \\
\text { expression of BDNF and mature oligodendrocytes, reduces OPC, inhibits brain JAK/ } \\
\text { STAT1/3, and reduces pro-inflammatory cytokines }\end{array}$ & Qu et al. (2019) \\
\hline Icariin & $\mathrm{CPZ}$ & $\begin{array}{l}\text { Improves the recovery of myelin, enhances the repair of NF200 positive axons, increases } \\
\text { the number of mature oligodendrocytes in APC/Olig2, and prevents the loss of neuron- } \\
\text { derived neurotrophic factors (such as NGF) }\end{array}$ & Zhang et al. (2017) \\
\hline Icariin & EAE & $\begin{array}{l}\text { Reduces microglia infiltration and spinal cord inflammation and demyelination, and } \\
\text { inhibits Th1 and Th17 cells differentiation }\end{array}$ & $\begin{array}{l}\text { Shen et al. (2015); Cong et al. } \\
\text { (2020) }\end{array}$ \\
\hline Pulsatilla saponin A3 & EAE & Inhibits inflammatory Th1 and Th17 responses and transforms Th1 into Th2 & Ip et al. (2015); Ip et al. (2017) \\
\hline $\begin{array}{l}\text { Dendrosomal nano- } \\
\text { curcumin (DNC) }\end{array}$ & $\mathrm{CPZ}$ & $\begin{array}{l}\text { Inhibits the activation of astrocytes and microglia and protects oligodendrocytes and } \\
\text { myelin cells }\end{array}$ & Motavaf et al. (2020) \\
\hline Bilobalide & EAE & $\begin{array}{l}\text { Inhibits the infiltration of } \mathrm{T} \text { cells and macrophages, reduces the expansion of } \\
\text { neuroinflammation, and causes the apoptosis of oligodendrocytes in the CNS }\end{array}$ & Miao et al. (2020) \\
\hline 6-Gingerol & EAE & $\begin{array}{l}\text { Inhibits the entry of inflammatory cells from the periphery into the CNS, inhibits the } \\
\text { activation of DCs, and induces tolerance }\end{array}$ & Han et al. (2019) \\
\hline Artemisinin & EAE & $\begin{array}{l}\text { Inhibits inflammatory Th1 and Th17 responses and transforms immune responsive Th1 } \\
\text { into Th2 cells }\end{array}$ & Khakzad et al. (2017) \\
\hline 9,10-Anhydrodehydroartemisinin & EAE & $\begin{array}{l}\text { Reduces the levels of CNS and peripheral immune system infiltrating inflammatory cells } \\
\text { Th1 and Th17 }\end{array}$ & Lv et al. (2021) \\
\hline Artesunate & EAE & Inhibits the migration of pathogenic T cells into the CNS & Thome et al. (2016) \\
\hline
\end{tabular}

EAE, experimental autoimmune encephalomyelitis; CPZ, cuprizone; Th, helper T cells; IL, interleukin; CD, cluster of differentiation; AMPK, adenosine monophosphate-activated protein kinase; DCs, dendritic cells; BDNF, brain-derived neurotrophic factor; CNS, central nervous system; OPC, oligodendrocyte progenitor cell; NF200, neurofilament 200 kDa; APC, antigenpresenting cells; Olig2, oligodendrocyte transcription factor-2; NGF, nerve growth factor.

immune induction and maintain immune homeostasis. Increasing evidence has shown that DCs play an important role in the pathogenesis of MS and it is the balance cells between Th1/Th2 and Th17/Treg. MS is an autoimmune disease mediated by Th cells. Therefore, the treatment of MS with DCs as targets has become a research hotspot. DCs are 
divided into immature DCs, mature DCs, and semi-mature DCs according to their state of maturity. The main function of immature DCs is antigen presentation, whereas the main function of mature DCs is to induce $\mathrm{T}$ cell activation. Based on their phenotypic function, they can be divided into two categories: conventional DCs and plasmacytoid DCs (Macri et al., 2016; Rosa et al., 2020).

Kim et al. (Kim et al., 2016) found that minocycline-treated DCs (Mino-DCs) could induce the differentiation of Foxp $3^{+}$ $\mathrm{T}$ cells with low expression of $\mathrm{MHC}$ II and costimulatory molecules and high expression of PDL-1. Injection of $\mathrm{MOG}_{35-}$

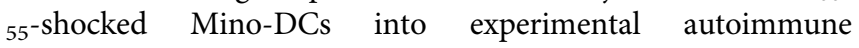
encephalomyelitis (EAE) mice could improve the clinical symptoms of EAE. Krivenko et al. (Krivenko et al., 2020) evaluated the effect of fluoxetine on the production of IL-6 and IL- $1 \beta$ by DCs in MS and showed that the compound could inhibit the production of these cytokines, indicating that fluoxetine could exert an anti-inflammatory effect on MS by regulating the production of pro-inflammatory cytokines by DCs. Further, Chen et al. (Chen et al., 2018) showed that DCs treated with atorvastatin maintained a stable semi-phenotype and low levels of costimulatory molecules and pro-inflammatory cytokines. The drug significantly reduced disease activity in EAE mice, regulated Th17/Treg balance, significantly reduced Th17 cells, and increased regulatory T cells, which is expected to become a new strategy for the treatment of MS in the future. Additionally, Wang et al. (Wang et al., 2016) showed that daphnetin could significantly inhibit the reaction of Th1 and Th17 cells as well as the activation, maturation, and antigen presentation of DCs. At the same time, NF- $\kappa B$ signal decreased significantly in DCs treated with daphnetin accompanied by the induction of heme oxygenase-1 (a negative regulator of inflammatory signal). Mondal et al. (Mondal et al., 2018) have also reported that aspirin reduces the development of EAE driven by myelin basic protein-specific T cells, increases the amount of Foxp3 and IL-4 in T cells, and inhibits the differentiation of $\mathrm{T}$ cells into helper T cells (Th17 and Th1 cells).

\section{MS Drugs Acting on Astrocytes and Microglia}

The exact etiology and pathogenesis of MS remain unclear. Its possible pathological features include the activation of astrocytes and microglia. A variety of pro-inflammatory and antiinflammatory cytokines and chemokines secreted by activated astrocytes and microglia can be used as direct or indirect immune mediators or inflammatory mediators in the pathogenesis of MS (Yi et al., 2019). In addition, Magnus et al. (Magnus et al., 2004) suggested that both microglia and astrocytes could absorb apoptotic cells, and the phagocytosis of microglia and astrocytes is determined by the nearby microenvironment, both of which play important roles in the occurrence and development of MS.

EAE and toxic demyelination induced by cuprizone (CPZ) are commonly used in animal models of MS that are used to study demyelination and remyelination during the infiltration of inflammatory cells in the CNS. Wang et al. (Wang et al.,
2020) showed that fasudil could inhibit microglial-mediated neuroinflammation and promote astrocyte-derived nerve growth factor and ciliary neurotrophic factor in CPZinduced demyelination. Arsenic trioxide is used to treat a variety of autoimmune diseases. An et al. (An et al., 2020) showed that this compound could reduce demyelination, inflammation, microglial activation, and the expression of IL-2, IFN- $\gamma$, IL- $1 \beta$, IL- 6 , and TNF- $\alpha$ in EAE mice. It is expected to become a new drug for the treatment of MS. Honokiol, a nano-liposome developed by Hsiao et al. (Hsiao et al., 2020), is a drug that could reduce the number of IL- $6^{+}$, Iba- $1^{+} \mathrm{TNF}^{+}, \mathrm{Iba}_{-}{ }^{+}$IL-12 $\mathrm{p}^{+} 0^{+}$, and $\mathrm{CD}^{+}$IFN- $\gamma+$ cells infiltrating the spinal cord and clearing the inhibitory effect of nanosome-encapsulated honokiol on the infiltration of activated microglia and Th1 cells into the spinal cord. Studies on microglia have shown that resveratrol-treated microglia can significantly inhibit the production of nitric oxide and TNF-a (Pallares et al., 2012). The same study emphasized the inhibitory effect of resveratrol on NF- $\kappa$ B in microglia (Nishikawa et al., 2015). In our laboratory, we found that cornel iridoid glycoside, icariin, and epimedium flavonoids could improve the symptoms of neurological damage in EAE and CPZ mice and inhibit the over-activation of microglia and astrocytes in the brain; thus, they may be potential effective drugs for the treatment of MS (Yin et al., 2012; Yin et al., 2014; Liang et al., 2015; Qu et al., 2016; Zhang et al., 2017; Qu et al., 2019).

\section{MS Drugs Acting on Oligodendrocytes}

Oligodendrocytes wrap nerve fibers in the CNS with a special cell membrane to form a myelin sheath. In MS, the loss of myelin and oligodendrocytes impairs jumping signal transduction, leading to neuronal loss and dysfunction (Yeung et al., 2019). The limited ability of oligodendrocyte progenitor cells to differentiate into mature cells is the main reason for the low efficiency of myelin repair in the CNS. Oligodendrocytes are important cells for the regeneration of myelin sheath and axons. To ensure myelin regeneration, oligodendrocyte progenitor cells must migrate from the demyelinating area of the subependymal zone of the lateral ventricle and then mature into oligodendrocytes to promote myelin regeneration.

Manousi et al. (Manousi et al., 2021) identified some new small molecules that could promote oligodendrocyte differentiation, even in the presence of the oligodendrocyte differentiation inhibitor p57Kip2 and found subsets that could promote human oligodendrocyte genesis and myelin formation in vitro. Among them, danazol and parbendazole promote oligodendrocyte differentiation and myelin repair. It has been reported that astaxanthin has a protective effect against neurodegenerative diseases and can reduce CNS damage caused by oxidative stress. Lotfi et al. (Lotfi et al., 2021) showed that astaxanthin plays a beneficial role in reducing demyelination and oligodendrocyte death in an MS rat model. Astragalus polysaccharides are the main bioactive components of the astragalus membrane, which can prevent demyelination in EAE and CPZ mice. Ye et al. (Ye et al., 2021) showed that astragalus polysaccharides inhibited the dryness of neural stem cells and promoted the differentiation of neural stem cells into 
oligodendrocytes and neurons. Ghaiad et al. (Ghaiad et al., 2017) also showed that resveratrol could increase the expression of oligodendrocyte transcription factor-1 and promote myelin regeneration, which has a potential value in the treatment of MS.

In summary, the adaptive immune response $\mathrm{T}$ and $\mathrm{B}$ cells as well as myeloid cells of the innate immune system (dendritic cells, astrocytes, and microglia) are not only components of the CNS but also participate in the regulation of neuroimmune inflammatory response as immune helper cells in the CNS. Their roles in the occurrence and development of MS cannot be ignored. However, to date, the mechanism of their action in MS is not yet completely clear, and the therapeutic target is still vague. Therefore, the target of effective intervention in their pathogenic process, that is promoting neuroprotection, could be a feasible treatment to alleviate MS, which may also be the target of drug development in the future. However, although a few studies based on the above exist, further experimental and clinical evidence is needed, which is expected to provide new ideas and strategies for the prevention and treatment of MS.

\section{Summary}

MS is characterized by peripheral and central inflammation, demyelination, and neurodegeneration. Although currently available MS treatments reduce the recurrence of the disease, they do not promote tolerance to myelin-specific $\mathrm{T}$ lymphocytes to ensure long-term protection against MS. Therefore, the treatment of MS is one of the biggest treatment challenges. To develop new and effective treatments for patients with MS, the mechanism of the disease needs to be fully clarified and understood, which may be multifactorial. However, the incomplete understanding of the pathogenesis of MS and lack of suitable animal models make it difficult to identify potential target pathways and new therapeutic drugs. Although the clinical use of some MS treatment drugs can alleviate the process of the disease,

\section{REFERENCES}

Aharoni, R. (2013). The Mechanism of Action of Glatiramer Acetate in Multiple Sclerosis and Beyond. Autoimmun. Rev. 12 (5), 543-553. doi:10.1016/ j.autrev.2012.09.005

Al-Ghezi, Z. Z., Busbee, P. B., Alghetaa, H., Nagarkatti, P. S., and Nagarkatti, M. (2019). Combination of Cannabinoids, Delta-9-Tetrahydrocannabinol (Thc) and Cannabidiol (Cbd), Mitigates Experimental Autoimmune Encephalomyelitis (Eae) by Altering the Gut Microbiome. Brain Behav. Immun. 82, 25-35. doi:10.1016/j.bbi.2019.07.028

An, K., Xue, M.-J., Zhong, J.-Y., Yu, S.-N., Lan, T.-S., Qi, Z.-Q., et al. (2020). Arsenic Trioxide Ameliorates Experimental Autoimmune Encephalomyelitis in C57BL/ 6 Mice by Inducing CD4+ T Cell Apoptosis. J. Neuroinflammation 17 (1), 147. doi:10.1186/s12974-020-01829-x

Antonio García Merino, J. (2014). Tratamiento actual de la esclerosis múltiple. Medicina Clínica 143 (Suppl. 3), 19-22. doi:10.1016/S0025-7753(15)30005-1

Bagherpour, B., Salehi, M., Jafari, R., Bagheri, A., Kiani-Esfahani, A., Edalati, M., et al. (2018). Promising Effect of Rapamycin on Multiple Sclerosis. Mult. Scler. Relat. Disord. 26, 40-45. doi:10.1016/j.msard.2018.08.009

Baldassari, L. E., and Fox, R. J. (2018). Therapeutic Advances and Challenges in the Treatment of Progressive Multiple Sclerosis. Drugs 78 (15), 1549-1566. doi:10.1007/s40265-018-0984-5

Bar-Or, A., Pachner, A., Menguy-Vacheron, F., Kaplan, J., and Wiendl, H. (2014). Teriflunomide and its Mechanism of Action in Multiple Sclerosis. Drugs 74 (6), 659-674. doi:10.1007/s40265-014-0212-x but they cannot completely cure MS and cause adverse reactions; thus, it is particularly important to actively seek safe and effective drugs for MS treatment. In summary, in view of the significant effects of drugs on autoimmunity and the regulation of the immune system, immunomodulatory drugs are expected to become candidates for the treatment of major autoimmune diseases. Although it is still a major challenge to develop effective strategies for the treatment of autoimmune diseases, such as MS, the complex immune regulation of drugs targeting various pathways in the treatment of autoimmune diseases is of great significance. Therefore, we have good reasons and are motivated to expand our exploration of drugs regulating the immune system to study and develop effective drugs for the treatment of MS.

\section{AUTHOR CONTRIBUTIONS}

WW conceived the presented idea and was responsible for manuscript preparation and literature search. DM aided in manuscript preparation, literature search, and manuscript revision. LL and LZ assisted in literature review and provided revisions and conceived of the review and provided feedback and revisions to the manuscript. All authors contributed to and have approved the final manuscript.

\section{FUNDING}

This study was supported by National Natural Science Foundation of China (81473373, 81874351, 81673406); National Science and Technology Major Project of China (No. 2015ZX09101-016); Capital Science and Technology Leading Talent Training Project (Z191100006119017), and Beijing Hospitals Authority Ascent Plan (DFL20190803).

Beer, K., Müller, M., Hew-Winzeler, A. M., Bont, A., Maire, P., You, X., et al. (2011). The Prevalence of Injection-Site Reactions with Disease-Modifying Therapies and Their Effect on Adherence in Patients with Multiple Sclerosis: An Observational Study. BMC Neurol. 11, 144. doi:10.1186/1471-2377-11-144 Bigaut, K., De Seze, J., and Collongues, N. (2019). Ocrelizumab for the Treatment of Multiple Sclerosis. Expert Rev. Neurotherapeutics 19 (2), 97-108. doi:10.1080/14737175.2019.1561284

Bittner, S., Afzali, A. M., Wiendl, H., and Meuth, S. G. (2014). Myelin Oligodendrocyte Glycoprotein (MOG35-55) Induced Experimental Autoimmune Encephalomyelitis (EAE) in C57bl/6 Mice. J. Vis. Exp. (86), 51275. doi:10.3791/51275

Boster, A., Nicholas, J., Wu, N., Yeh, W.-S., Fay, M., Edwards, M., et al. (2017). Comparative Effectiveness Research of Disease-Modifying Therapies for the Management of Multiple Sclerosis: Analysis of a Large Health Insurance Claims Database. Neurol. Ther. 6 (1), 91-102. doi:10.1007/s40120-017-0064-x

Burns, S. A., Lee Archer, R., Chavis, J. A., Tull, C. A., Hensley, L. L., and Drew, P. D. (2012). Mitoxantrone Repression of Astrocyte Activation: Relevance to Multiple Sclerosis. Brain Res. 1473, 236-241. doi:10.1016/j.brainres.2012.07.054

Buron, M. D., Kalincik, T., Sellebjerg, F., Sørensen, P. S., and Magyari, M. (2021). Effect of Lateral Therapy Switches to Oral Moderate-Efficacy Drugs in Multiple Sclerosis: A Nationwide Cohort Study. J. Neurol. Neurosurg. Psychiatry 92 (5), 556-562. doi:10.1136/jnnp-2020-324869

Chataway, J., De Angelis, F., Connick, P., Parker, R. A., Plantone, D., Doshi, A., et al. (2020). Efficacy of Three Neuroprotective Drugs in Secondary Progressive Multiple Sclerosis (Ms-Smart): A Phase 2b, Multiarm, Double-Blind, 
Randomised Placebo-Controlled Trial. Lancet Neurol. 19 (3), 214-225. doi:10.1016/S1474-4422(19)30485-5

Chataway, J., Schuerer, N., Alsanousi, A., Chan, D., MacManus, D., Hunter, K., et al. (2014). Effect of High-Dose Simvastatin on Brain Atrophy and Disability in Secondary Progressive Multiple Sclerosis (Ms-Stat): A Randomised, PlaceboControlled, Phase 2 Trial. The Lancet 383 (9936), 2213-2221. doi:10.1016/ S0140-6736(13)62242-4

Chen, Z., Yang, D., Peng, X., Lin, J., Su, Z., Li, J., et al. (2018). Beneficial Effect of Atorvastatin-Modified Dendritic Cells Pulsed with Myelin Oligodendrocyte Glycoprotein Autoantigen on Experimental Autoimmune Encephalomyelitis. Neuroreport 29 (4), 317-327. doi:10.1097/WNR.0000000000000962

Chisari, C. G., Sgarlata, E., Arena, S., Toscano, S., Luca, M., and Patti, F. (2021). Rituximab for the Treatment of Multiple Sclerosis: A Review. J. Neurol. 1-25. doi:10.1007/s00415-020-10362-z

Cohan, S. (2016). Therapeutic Efficacy of Monthly Subcutaneous Injection of Daclizumab in Relapsing Multiple Sclerosis. Btt 10, 119-138. doi:10.2147/ BTT.S89218

Cohen, J. A., Barkhof, F., Comi, G., Hartung, H.-P., Khatri, B. O., Montalban, X., et al. (2010). Oral Fingolimod or Intramuscular Interferon for Relapsing Multiple Sclerosis. N. Engl. J. Med. 362 (5), 402-415. doi:10.1056/ NEJMoa0907839

Cohen, J. A., Khatri, B., Barkhof, F., Comi, G., Hartung, H.-P., Montalban, X., et al. (2016). Long-Term (Up to 4.5 Years) Treatment with Fingolimod in Multiple Sclerosis: Results from the Extension of the Randomised Transforms Study. J. Neurol. Neurosurg. Psychiatry 87 (5), 468-475. doi:10.1136/jnnp-2015-310597

Comi, G., Cohen, J. A., Arnold, D. L., Wynn, D., Filippi, M., and Group, F. S. (2011). Phase Iii Dose-Comparison Study of Glatiramer Acetate for Multiple Sclerosis. Ann. Neurol. 69 (1), 75-82. doi:10.1002/ana.22316

Confavreux, C., Li, D. K., Freedman, M. S., Truffinet, P., Benzerdjeb, H., Wang, D., et al. (2012). Long-Term Follow-Up of a Phase 2 Study of Oral Teriflunomide in Relapsing Multiple Sclerosis: Safety and Efficacy Results up to 8.5 Years. Mult. Scler. 18 (9), 1278-1289. doi:10.1177/1352458512436594

Confavreux, C., O'Connor, P., Comi, G., Freedman, M. S., Miller, A. E., Olsson, T. P., et al. (2014). Oral Teriflunomide for Patients with Relapsing Multiple Sclerosis (Tower): A Randomised, Double-Blind, Placebo-Controlled, Phase 3 Trial. Lancet Neurol. 13 (3), 247-256. doi:10.1016/S14744422(13)70308-9

Cong, H., Zhang, M., Chang, H., Du, L., Zhang, X., and Yin, L. (2020). Icariin Ameliorates the Progression of Experimental Autoimmune Encephalomyelitis by Down-Regulating the Major Inflammatory Signal Pathways in a Mouse Relapse-Remission Model of Multiple Sclerosis. Eur. J. Pharmacol. 885, 173523. doi:10.1016/j.ejphar.2020.173523

Correale, J., Gaitán, M. I., Ysrraelit, M. C., and Fiol, M. P. (2017). Progressive Multiple Sclerosis: From Pathogenic Mechanisms to Treatment. Brain 140 (3), 527-546. doi:10.1093/brain/aww258

Cunniffe, N., Vuong, K. A., Ainslie, D., Baker, D., Beveridge, J., Bickley, S., et al. (2021). Systematic Approach to Selecting Licensed Drugs for Repurposing in the Treatment of Progressive Multiple Sclerosis. J. Neurol. Neurosurg. Psychiatry 92 (3), 295-302. doi:10.1136/jnnp-2020-324286

De Andres, C., García, M. I., Goicoechea, H., Martínez-Ginés, M. L., GarcíaDomínguez, J. M., Martín, M. L., et al. (2018). Genes Differentially Expressed by Methylprednisolone In Vivo in Cd4 T Lymphocytes from Multiple Sclerosis Patients: Potential Biomarkers. Pharmacogenomics J. 18 (1), 98-105. doi:10.1038/tpj.2016.71

De Angelis, F., Plantone, D., and Chataway, J. (2018). Pharmacotherapy in Secondary Progressive Multiple Sclerosis: An Overview. CNS Drugs 32 (6), 499-526. doi:10.1007/s40263-018-0538-0

Dendrou, C. A., Fugger, L., and Friese, M. A. (2015). Immunopathology of Multiple Sclerosis. Nat. Rev. Immunol. 15 (9), 545-558. doi:10.1038/nri3871

Dobson, R., and Giovannoni, G. (2019). Multiple Sclerosis - A Review. Eur. J. Neurol. 26 (1), 27-40. doi:10.1111/ene.13819

Edan, G., Morrissey, S., and Le Page, E. (2004). Rationale for the Use of Mitoxantrone in Multiple Sclerosis. J. Neurol. Sci. 223 (1), 35-39. doi:10.1016/j.jns.2004.04.017

Filippini, G., Del Giovane, C., Clerico, M., Beiki, O., Mattoscio, M., Piazza, F., et al. (2017). Treatment with Disease-Modifying Drugs for People with a First Clinical Attack Suggestive of Multiple Sclerosis. Cochrane Database Syst. Rev. 4 (4), CD012200. doi:10.1002/14651858.CD012200.pub2
Findling, O., Hauer, L., Pezawas, T., Rommer, P. S., Struhal, W., and Sellner, J. (2020). Cardiac Autonomic Dysfunction in Multiple Sclerosis: A Systematic Review of Current Knowledge and Impact of Immunotherapies. Jcm 9 (2), 335. doi: $10.3390 / \mathrm{jcm} 9020335$

Findling, O., and Sellner, J. (2021). Second-Generation Immunotherapeutics in Multiple Sclerosis: Can We Discard Their Precursors?. Drug Discov. Today 26 (2), 416-428. doi:10.1016/j.drudis.2020.11.022

Fox, R. J., Coffey, C. S., Conwit, R., Cudkowicz, M. E., Gleason, T., Goodman, A., et al. (2018). Phase 2 Trial of Ibudilast in Progressive Multiple Sclerosis. N. Engl. J. Med. 379 (9), 846-855. doi:10.1056/NEJMoa1803583

Gajofatto, A., and Benedetti, M. D. (2015). Treatment Strategies for Multiple Sclerosis: When to Start, When to Change, When to Stop? Wjcc 3 (7), 545-555. doi:10.12998/wjcc.v3.i7.545

Gerdes, L. A., Held, K., Beltrán, E., Berking, C., Prinz, J. C., Junker, A., et al. (2016). Ctla4 as Immunological Checkpoint in the Development of Multiple Sclerosis. Ann. Neurol. 80 (2), 294-300. doi:10.1002/ana.24715

Ghaiad, H. R., Nooh, M. M., El-Sawalhi, M. M., and Shaheen, A. A. (2017). Resveratrol Promotes Remyelination in Cuprizone Model of Multiple Sclerosis: Biochemical and Histological Study. Mol. Neurobiol. 54 (5), 3219-3229. doi:10.1007/s12035-016-9891-5

Gold, R., Stefoski, D., Selmaj, K., Havrdova, E., Hurst, C., Holman, J., et al. (2016). Pregnancy Experience: Nonclinical Studies and Pregnancy Outcomes in the Daclizumab Clinical Study Program. Neurol. Ther. 5 (2), 169-182. doi:10.1007/ s40120-016-0048-2

Gold, R., and Wolinsky, J. S. (2011). Pathophysiology of Multiple Sclerosis and the Place of Teriflunomide. Acta Neurol. Scand. 124 (2), 75-84. doi:10.1111/j.16000404.2010.01444.x

Gross, C. C., Ahmetspahic, D., Ruck, T., Schulte-Mecklenbeck, A., Schwarte, K., Jörgens, S., et al. (2016). Alemtuzumab Treatment Alters Circulating Innate Immune Cells in Multiple Sclerosis. Neurol. Neuroimmunol Neuroinflamm 3 (6), e289. doi:10.1212/NXI.0000000000000289

Gyetvai, G., Roe, C., Heikal, L., Ghezzi, P., and Mengozzi, M. (2018). Leukemia Inhibitory Factor Inhibits Erythropoietin-Induced Myelin Gene Expression in Oligodendrocytes. Mol. Med. 24 (1), 51. doi:10.1186/ s10020-018-0052-3

Han, J. J., Li, X., Ye, Z. Q., Lu, X. Y., Yang, T., Tian, J., et al. (2019). Treatment with 6-Gingerol Regulates Dendritic Cell Activity and Ameliorates the Severity of Experimental Autoimmune Encephalomyelitis. Mol. Nutr. Food Res. 63 (18), e1801356. doi:10.1002/mnfr.201801356

Hosseini, A., Gharibi, T., Mohammadzadeh, A., Ebrahimi-Kalan, A., JadidiNiaragh, F., Babaloo, Z., et al. (2021). Ruxolitinib Attenuates Experimental Autoimmune Encephalomyelitis (Eae) Development as Animal Models of Multiple Sclerosis (Ms). Life Sci. 276, 119395. doi:10.1016/ j.lfs.2021.119395

Hsiao, Y.-P., Chen, H.-T., Liang, Y.-C., Wang, T.-E., Huang, K.-H., Hsu, C.-C., et al. (2020). Development of Nanosome-Encapsulated Honokiol for Intravenous Therapy against Experimental Autoimmune Encephalomyelitis. Ijn 15, 17-29. doi:10.2147/IJN.S214349

Hupperts, R., Smolders, J., Vieth, R., Holmøy, T., Marhardt, K., Schluep, M., et al. (2019). Randomized Trial of Daily High-Dose Vitamin D3 in Patients with RRMS Receiving Subcutaneous Interferon $\beta$-1a. Neurology 93 (20), e1906-e1916. doi:10.1212/WNL.0000000000008445

Imeri, F., Stepanovska Tanturovska, B., Zivkovic, A., Enzmann, G., Schwalm, S., Pfeilschifter, J., et al. (2021). Novel Compounds with Dual S1p Receptor Agonist and Histamine H3 Receptor Antagonist Activities Act Protective in a Mouse Model of Multiple Sclerosis. Neuropharmacology 186, 108464. doi:10.1016/j.neuropharm.2021.108464

Ip, F. C. F., Ng, Y. P., Or, T. C. T., Sun, P., Fu, G., Li, J. Y. H., et al. (2017). Anemoside A3 Ameliorates Experimental Autoimmune Encephalomyelitis by Modulating T Helper 17 Cell Response. PLoS One 12 (7), e0182069. doi:10.1371/journal.pone.0182069

Ip, F. C., Fu, W.-Y., Cheng, E. Y., Tong, E. P., Lok, K.-C., Liang, Y., et al. (2015). Anemoside A3 Enhances Cognition Through the Regulation of Synaptic Function and Neuroprotection. Neuropsychopharmacol 40 (8), 1877-1887. doi:10.1038/npp.2015.37

Jain, A., and Jain, S. (2008). Pegylation: An Approach for Drug Delivery. A Review. Crit. Rev. Ther. Drug Carrier Syst. 25 (5), 403-447. doi:10.1615/ critrevtherdrugcarriersyst.v25.i5.10 
Jayaraman, A., Soni, A., Prabhakar, B. S., Holterman, M., and Jayaraman, S. (2017). The Epigenetic Drug Trichostatin a Ameliorates Experimental Autoimmune Encephalomyelitis via $\mathrm{T}$ Cell Tolerance Induction and Impaired Influx of T Cells into the Spinal Cord. Neurobiol. Dis. 108, 1-12. doi:10.1016/ j.nbd.2017.07.015

Jeffery, D. R., and Herndon, R. (2004). Review of Mitoxantrone in the Treatment of Multiple Sclerosis. Neurology 63 (12 Suppl. 6), S19-S24. doi:10.1212/ wnl.63.12_suppl_6.s19

Jolivel, V., Luessi, F., Masri, J., Kraus, S. H. P., Hubo, M., Poisa-Beiro, L., et al. (2013). Modulation of Dendritic Cell Properties by Laquinimod as a Mechanism for Modulating Multiple Sclerosis. Brain 136 (Pt 4), 1048-1066. doi:10.1093/brain/awt023

Khakzad, M. R., Ganji, A., Ariabod, V., and Farahani, I. (2017). Artemisinin Therapeutic Efficacy in the Experimental Model of Multiple Sclerosis. Immunopharmacology and Immunotoxicology 39 (6), 348-353. doi:10.1080/ 08923973.2017.1379087

Kidd, T., Carey, N., Mold, F., Westwood, S., Miklaucich, M., Konstantara, E., et al. (2017). A Systematic Review of the Effectiveness of Self-Management Interventions in People with Multiple Sclerosis at Improving Depression, Anxiety and Quality of Life. PLoS One 12 (10), e0185931. doi:10.1371/ journal.pone.0185931

Kim, M.-J., Sung, J.-J., Kim, S. H., Kim, J.-M., Jeon, G. S., Mun, S.-K., et al. (2017). The Anti-inflammatory Effects of Oral-Formulated Tacrolimus in Mice with Experimental Autoimmune Encephalomyelitis. J. Korean Med. Sci. 32 (9), 1502-1507. doi:10.3346/jkms.2017.32.9.1502

Kim, N., Park, C.-S., Im, S.-A., Kim, J.-W., Lee, J.-H., Park, Y.-J., et al. (2016). Minocycline Promotes the Generation of Dendritic Cells with Regulatory Properties. Oncotarget 7 (33), 52818-52831. doi:10.18632/oncotarget.10810

Klotz, L., Havla, J., Schwab, N., Hohlfeld, R., Barnett, M., Reddel, S., et al. (2019). Risks and Risk Management in Modern Multiple Sclerosis Immunotherapeutic Treatment. Ther. Adv. Neurol. Disord. 12, 175628641983657. doi:10.1177/ 1756286419836571

Krivenko, L. V., Sviridova, A. A., Melnikov, M. V., Rogovskii, V. S., Boyko, A. N., and Pashenkov, M. V. (2020). The Influence of Fluoxetine on Interleukin-6 and Interleukin- $1 \beta$ Production by Dendritic Cells in Multiple Sclerosis In Vitro. $Z$. Nevrol. Psikhiatr. Im. S.S. Korsakova 120 (7), 67-72. doi:10.17116/ jnevro202012007267

Krysko, K. M., Graves, J. S., Rensel, M., Weinstock-Guttman, B., Rutatangwa, A., Aaen, G., et al. (2020). Real-World Effectiveness of Initial Disease-Modifying Therapies in Pediatric Multiple Sclerosis. Ann. Neurol. 88 (1), 42-55. doi:10.1002/ana.25737

La Mantia, L., Di Pietrantonj, C., Rovaris, M., Rigon, G., Frau, S., Berardo, F., et al. (2015). Comparative Efficacy of Interferon $\beta$ Versus Glatiramer Acetate for Relapsing-Remitting Multiple Sclerosis. J. Neurol. Neurosurg. Psychiatry 86 (9), 1016-1020. doi:10.1136/jnnp-2014-309243

La Mantia, L., Milanese, C., Mascoli, N., D'Amico, R., and Weinstock-Guttman, B. (2007). Cyclophosphamide for Multiple Sclerosis. Cochrane Database Syst. Rev. 2007 (1), CD002819. doi:10.1002/14651858.CD002819.pub2

Lamb, Y. N. (2020). Ozanimod: First Approval. Drugs 80 (8), 841-848. doi:10.1007/ s40265-020-01319-7

Largani, S. H. H., Borhani-Haghighi, M., Pasbakhsh, P., Mahabadi, V. P., Nekoonam, S., Shiri, E., et al. (2019). Oligoprotective Effect of Metformin Through the Ampk-dependent on Restoration of Mitochondrial Hemostasis in the Cuprizone-Induced Multiple Sclerosis Model. J. Mol. Hist. 50 (3), 263-271. doi:10.1007/s10735-019-09824-0

Li, X.-l., Zhang, B., Liu, W., Sun, M.-j., Zhang, Y.-l., Liu, H., et al. (2020). Rapamycin Alleviates the Symptoms of Multiple Sclerosis in Experimental Autoimmune Encephalomyelitis (Eae) Through Mediating the Tam-Tlrs-Socs Pathway. Front. Neurol. 11, 590884. doi:10.3389/fneur.2020.590884

Liang, M., Chen, Y., Zhang, L., Li, L., Chen, G., and Yin, L. (2015). Epimedium Flavonoids Ameliorate Neuropathological Changes and Increases Igf-1 Expression in C57bl/6 Mice Exposed to Cuprizone. Neurochem. Res. 40 (3), 492-500. doi:10.1007/s11064-014-1490-0

Lombardo, S. D., Mazzon, E., Basile, M. S., Campo, G., Corsico, F., Presti, M., et al. (2019). Modulation of Tetraspanin 32 (Tspan32) Expression in T CellMediated Immune Responses and in Multiple Sclerosis. Ijms 20 (18), 4323. doi:10.3390/ijms 20184323
Lotfi, A., Soleimani, M., and Ghasemi, N. (2021). Astaxanthin Reduces Demyelination and Oligodendrocytes Death in a Rat Model of Multiple Sclerosis. Cell J 22 (4), 565-571. doi:10.22074/cellj.2021.6999

Lühder, F., Kebir, H., Odoardi, F., Litke, T., Sonneck, M., Alvarez, J. I., et al. (2017). Laquinimod Enhances Central Nervous System Barrier Functions. Neurobiol. Dis. 102, 60-69. doi:10.1016/j.nbd.2017.02.002

Lv, J., Zhuang, W., Zhang, Y., Xie, L., Xiang, Z., Zhao, Q., et al. (2021). 9,10Anhydrodehydroartemisinin Attenuates Experimental Autoimmune Encephalomyelitis by Inhibiting Th1 and Th17 Cell Differentiation. Inflammation. doi:10.1007/s10753-021-01456-5

Macri, C., Dumont, C., Johnston, A. P., and Mintern, J. D. (2016). Targeting Dendritic Cells: A Promising Strategy to Improve Vaccine Effectiveness. Clin. Trans. Immunol. 5 (3), e66. doi:10.1038/cti.2016.6

Magnus, T., Korn, T., and Jung, S. (2004). Chronically Stimulated Microglial Cells Do No Longer Alter Their Immune Functions in Response to the Phagocytosis of Apoptotic Cells. J. Neuroimmunology 155 (1-2), 64-72. doi:10.1016/ j.jneuroim.2004.06.002

Manousi, A., Göttle, P., Reiche, L., Cui, Q.-L., Healy, L. M., Akkermann, R., et al. (2021). Identification of Novel Myelin Repair Drugs by Modulation of Oligodendroglial Differentiation Competence. EBioMedicine 65, 103276. doi:10.1016/j.ebiom.2021.103276

Martinelli, V., Radaelli, M., Straffi, L., Rodegher, M., and Comi, G. (2009). Mitoxantrone: Benefits and Risks in Multiple Sclerosis Patients. Neurol. Sci. 30 (Suppl. 2), 167-170. doi:10.1007/s10072-009-0142-7

Matko, S., Akgün, K., Tonn, T., Ziemssen, T., and Odendahl, M. (2020). AntigenShift in Varicella-Zoster Virus-specific T-Cell Immunity over the Course of Fingolimod-Treatment in Relapse-Remitting Multiple Sclerosis Patients. Mult. Scler. Relat. Disord. 38, 101859. doi:10.1016/j.msard.2019.101859

Menge, T., Rehberg-Weber, K., Taipale, K., Nastos, I., and Jauss, M. (2021). Peginterferon Beta-1a Was Associated with High Adherence and Satisfaction in Patients with Multiple Sclerosis in a German Real-World Study. Ther. Adv. Neurol. Disord. 14, 175628642110004. doi:10.1177/ 17562864211000461

Menzin, J., Caon, C., Nichols, C., White, L. A., Friedman, M., and Pill, M. W. (2013). Narrative Review of the Literature on Adherence to Disease-Modifying Therapies Among Patients with Multiple Sclerosis. Jmcp 19 (1 Suppl. A), S24-S40. doi:10.18553/jmcp.2013.19.s1.S24

Miao, Q., Zhang, X.-X., Han, Q.-X., Ren, S.-S., Sui, R.-X., Yu, J.-W., et al. (2020). The Therapeutic Potential of Bilobalide on Experimental Autoimmune Encephalomyelitis (Eae) Mice. Metab. Brain Dis. 35 (5), 793-807. doi:10.1007/s11011-020-00555-w

Michel, L., Vukusic, S., De Seze, J., Ducray, F., Ongagna, J. C., Lefrere, F., et al. (2014). Mycophenolate Mofetil in Multiple Sclerosis: A Multicentre Retrospective Study on 344 Patients. J. Neurol. Neurosurg. Psychiatry 85 (3), 279-283. doi:10.1136/jnnp-2013-305298

Milo, R. (2015). Effectiveness of Multiple Sclerosis Treatment with Current Immunomodulatory Drugs. Expert Opin. Pharmacother. 16 (5), 659-673. doi:10.1517/14656566.2015.1002769

Miravalle, A. A., Katz, J., Robertson, D., Hayward, B., Harlow, D. E., Lebson, L. A., et al. (2021). Click-Ms and Master-2 Phase Iv Trial Design: Cladribine Tablets in Suboptimally Controlled Relapsing Multiple Sclerosis. Neurodegenerative Dis. Manag. 11 (2), 99-111. doi:10.2217/nmt-2020-0059

Mohr, D. C., Boudewyn, A. C., Likosky, W., Levine, E., and Goodkin, D. E. (2001). Injectable Medication for the Treatment of Multiple Sclerosis: The Influence of Self-Efficacy Expectations and Infection Anxiety on Adherence and Ability to Self-Inject. Ann. Behav. Med. 23 (2), 125-132. doi:10.1207/ S15324796ABM2302_7

Mondal, S., Jana, M., Dasarathi, S., Roy, A., and Pahan, K. (2018). Aspirin Ameliorates Experimental Autoimmune Encephalomyelitis Through Interleukin-11-Mediated Protection of Regulatory T Cells. Sci. Signal. 11 (558), eaar8278. doi:10.1126/scisignal.aar8278

Moransard, M., Bednar, M., Frei, K., Gassmann, M., and Ogunshola, O. O. (2017). Erythropoietin Reduces Experimental Autoimmune Encephalomyelitis Severity via Neuroprotective Mechanisms. J. Neuroinflammation 14 (1), 202. doi:10.1186/s12974-017-0976-5

Motavaf, M., Sadeghizadeh, M., Babashah, S., Zare, L., and Javan, M. (2020). Protective Effects of a Nano-Formulation of Curcumin Against Cuprizone- 
Induced Demyelination in the Mouse Corpus Callosum. Iranian J. Pharm. Res. 19 (3), 310-320. doi:10.22037/ijpr.2020.112952.14033

Myhr, K.-M. (2008). Diagnosis and Treatment of Multiple Sclerosis. Acta Neurol. Scand. 117, 12-21. doi:10.1111/j.1600-0404.2008.01026.x

Naismith, R. T., Bermel, R. A., Coffey, C. S., Goodman, A. D., Fedler, J., Kearney, M., et al. (2021). Effects of Ibudilast on Mri Measures in the Phase 2 Sprint-Ms Study. Neurology 96 (4), e491-e500. doi:10.1212/WNL.0000000000011314

Naismith, R. T., Wolinsky, J. S., Wundes, A., LaGanke, C., Arnold, D. L., Obradovic, D., et al. (2020a). Diroximel Fumarate (Drf) in Patients with Relapsing-Remitting Multiple Sclerosis: Interim Safety and Efficacy Results from the Phase 3 Evolve-Ms-1 Study. Mult. Scler. 26 (13), 1729-1739. doi:10.1177/1352458519881761

Naismith, R. T., Wundes, A., Wundes, A., Ziemssen, T., Jasinska, E., Freedman, M. S., et al. (2020b). Diroximel Fumarate Demonstrates an Improved Gastrointestinal Tolerability Profile Compared with Dimethyl Fumarate in Patients with Relapsing-Remitting Multiple Sclerosis: Results from the Randomized, Double-Blind, Phase Iii Evolve-Ms-2 Study. CNS Drugs 34 (2), 185-196. doi:10.1007/s40263-020-00700-0

Nishikawa, K., Iwaya, K., Kinoshita, M., Fujiwara, Y., Akao, M., Sonoda, M., et al. (2015). Resveratrol Increases CD68+Kupffer Cells Colocalized with Adipose Differentiation-Related Protein and Ameliorates High-Fat-Diet-Induced Fatty Liver in Mice. Mol. Nutr. Food Res. 59 (6), 1155-1170. doi:10.1002/ mnfr.201400564

O'Connor, P., Wolinsky, J. S., Confavreux, C., Comi, G., Kappos, L., Olsson, T. P., et al. (2011). Randomized Trial of Oral Teriflunomide for Relapsing Multiple Sclerosis. N. Engl. J. Med. 365 (14), 1293-1303. doi:10.1056/NEJMoa1014656

Oh, J., Vidal-Jordana, A., and Montalban, X. (2018). Multiple Sclerosis: Clinical Aspects. Curr. Opin. Neurol. 31 (6), 752-759. doi:10.1097/ WCO.0000000000000622

Pahan, S., and Pahan, K. (2019). Mode of Action of Aspirin in Experimental Autoimmune Encephalomyelitis. DNA Cel Biol. 38 (7), 593-596. doi:10.1089/ dna.2019.4814

Pallarès, V., Calay, D., Cedó, L., Castell-Auví, A., Raes, M., Pinent, M., et al. (2012). Enhanced Anti-inflammatory Effect of Resveratrol and Epa in Treated Endotoxin-Activated Raw 264.7 Macrophages. Br. J. Nutr. 108 (9), 1562-1573. doi:10.1017/S0007114511007057

Patel, A., Sul, J., Gordon, M. L., Steinklein, J., Sanguinetti, S., Pramanik, B., et al. (2021). Progressive Multifocal Leukoencephalopathy in a Patient with Progressive Multiple Sclerosis Treated with Ocrelizumab Monotherapy. JAMA Neurol. 78 (6), 736-740. doi:10.1001/jamaneurol.2021.0627

Paterka, M., Siffrin, V., Voss, J. O., Werr, J., Hoppmann, N., Gollan, R., et al. (2016). Gatekeeper Role of Brain Antigen-presenting CD11c + Cells in Neuroinflammation. EMBO J. 35 (1), 89-101. doi:10.15252/embj.201591488

Patti, F., and Lo Fermo, S. (2011). Lights and Shadows of Cyclophosphamide in the Treatment of Multiple Sclerosis. Autoimmune Dis. 2011, 1-14. doi:10.4061/ $2011 / 961702$

Patti, F. (2010). Optimizing the Benefit of Multiple Sclerosis Therapy: The Importance of Treatment Adherence. Ppa 4, 1-9. doi:10.2147/ppa.s8230

Pavelek, Z., Sobíšek, L., Šarláková, J., Potužník, P., Peterka, M., Štětkárová, I., et al. (2020). Comparison of Therapies in Ms Patients After the First Demyelinating Event in Real Clinical Practice in the Czech Republic: Data from the National Registry Remus. Front. Neurol. 11, 593527. doi:10.3389/ fneur.2020.593527

Qu, Z., Zheng, N., Wei, Y., Chen, Y., Zhang, Y., Zhang, M., et al. (2019). Effect of Cornel Iridoid Glycoside on Microglia Activation Through Suppression of the Jak/Stat Signalling Pathway. J. Neuroimmunology 330, 96-107. doi:10.1016/ j.jneuroim.2019.01.014

Qu, Z., Zheng, N., Zhang, Y., Zhang, L., Liu, J., Wang, Q., et al. (2016). Preventing the Bdnf and Ngf Loss Involved in the Effects of Cornel Iridoid Glycoside on Attenuation of Experimental Autoimmune Encephalomyelitis in Mice. Neurol. Res. 38 (9), 831-837. doi:10.1080/01616412.2016.1200766

Rommer, P. S., and Zettl, U. K. (2018). Managing the Side Effects of Multiple Sclerosis Therapy: Pharmacotherapy Options for Patients. Expert Opin. Pharmacother. 19 (5), 483-498. doi:10.1080/14656566.2018.1446944

Rosa, F., Pires, C., Zimmermannova, O., and Pereira, C.-F. (2020). Direct Reprogramming of Mouse Embryonic Fibroblasts to Conventional Type 1 Dendritic Cells by Enforced Expression of Transcription Factors. Bio-protocol 10 (10), e3619. doi:10.21769/BioProtoc.3619
Sato, D., Callegaro, D., Lana-Peixoto, M. A., and Fujihara, K. (2012). Brazilian Committee for, T., and Research in Multiple, S. (Treatment of Neuromyelitis Optica: An Evidence Based Review. Arq. Neuro-psiquiatr. 70 (1), 59-66. doi:10.1590/s0004-282x2012000100012

Shahi, S. K., Jensen, S. N., Murra, A. C., Tang, N., Guo, H., Gibson-Corley, K. N., et al. (2020). Human Commensal Prevotella Histicola Ameliorates Disease as Effectively as Interferon-Beta in the Experimental Autoimmune Encephalomyelitis. Front. Immunol. 11, 578648. doi:10.3389/fimmu.2020.578648

Shen, K., Reichelt, M., Kyauk, R. V., Ngu, H., Shen, Y.-A. A., Foreman, O., et al. (2021). Multiple Sclerosis Risk Gene Mertk Is Required for Microglial Activation and Subsequent Remyelination. Cel Rep. 34 (10), 108835. doi:10.1016/j.celrep.2021.108835

Shen, R., Deng, W., Li, C., and Zeng, G. (2015). A Natural Flavonoid Glucoside Icariin Inhibits Th1 and Th17 Cell Differentiation and Ameliorates Experimental Autoimmune Encephalomyelitis. Int. Immunopharmacology 24 (2), 224-231. doi:10.1016/j.intimp.2014.12.015

Shirani, A., Okuda, D. T., and Stüve, O. (2016). Therapeutic Advances and Future Prospects in Progressive Forms of Multiple Sclerosis. Neurotherapeutics 13 (1), 58-69. doi:10.1007/s13311-015-0409-z

Song, J. Y., Griffin, J. D., Larson, N. R., Christopher, M. A., Middaugh, C. R., and Berkland, C. J. (2020). Synthetic Cationic Autoantigen Mimics Glatiramer Acetate Persistence at the Site of Injection and Is Efficacious Against Experimental Autoimmune Encephalomyelitis. Front. Immunol. 11, 603029. doi:10.3389/fimmu.2020.603029

Spagnuolo, C., Moccia, S., and Russo, G. L. (2018). Anti-Inflammatory Effects of Flavonoids in Neurodegenerative Disorders. Eur. J. Med. Chem. 153, 105-115. doi:10.1016/j.ejmech.2017.09.001

Spampinato, S. F., Merlo, S., Sano, Y., Kanda, T., and Sortino, M. A. (2021). Protective Effect of the Sphingosine-1 Phosphate Receptor Agonist Siponimod on Disrupted Blood Brain Barrier Function. Biochem. Pharmacol. 186, 114465. doi:10.1016/j.bcp.2021.114465

Teymoori-Rad, M., Sahraian, M. A., Mokhtariazad, T., Nejati, A., Mozdabadi, R. S. K., Amiri, M. M., et al. (2021). Illuminating the In Vitro Effects of Epstein-Barr Virus and Vitamin D on Immune Response in Multiple Sclerosis Patients. J. Neurovirol. 27 (2), 260-271. doi:10.1007/s13365-021-00951-7

Thomé, R., de Carvalho, A. C., Alves da Costa, T., Ishikawa, L. L. W., Fraga-Silva, T. F. d. C., Sartori, A., et al. (2016). Artesunate Ameliorates Experimental Autoimmune Encephalomyelitis by Inhibiting Leukocyte Migration to the Central Nervous System. CNS Neurosci. Ther. 22 (8), 707-714. doi:10.1111/ cns. 12561

U.S. Food and Drug Administration (2020). FDA.Zeposia ${ }^{\circledR}$ (Ozanimod) Capsules, for Oral Use [EB/OL]. Available at: https://www.accessdata.fda.gov/drugsatfda_ docs/label/2020/209899s000lbl.pdf.

van Dijkman, S. C., de Jager, N. C. B., Rauwé, W. M., Danhof, M., and Della Pasqua, O. (2018). Effect of Age-Related Factors on the Pharmacokinetics of Lamotrigine and Potential Implications for Maintenance Dose Optimisation in Future Clinical Trials. Clin. Pharmacokinet. 57 (8), 1039-1053. doi:10.1007/ s40262-017-0614-5

Vergo, S., Craner, M. J., Etzensperger, R., Attfield, K., Friese, M. A., Newcombe, J., et al. (2011). Acid-Sensing Ion Channel 1 Is Involved in Both Axonal Injury and Demyelination in Multiple Sclerosis and its Animal Model. Brain 134 (Pt 2), 571-584. doi:10.1093/brain/awq337

Wang, D., Lu, Z., Zhang, H., Jin, S.-F., Yang, H., Li, Y.-M., et al. (2016). Daphnetin Alleviates Experimental Autoimmune Encephalomyelitis via Regulating Dendritic Cell Activity. CNS Neurosci. Ther. 22 (7), 558-567. doi:10.1111/ cns. 12537

Wang, J., Sui, R.-X., Miao, Q., Wang, Q., Song, L.-J., Yu, J.-Z., et al. (2019). RETRACTED: Hydroxyfasudil Alleviates Demyelination Through the Inhibition of MOG Antibody and Microglia Activation in Cuprizone Mouse Model. Clin. Immunol. 201, 35-47. doi:10.1016/j.clim.2019.01.006

Wang, J., Sui, R. X., Miao, Q., Wang, Q., Song, L. J., Yu, J. Z., et al. (2020). Retracted: Effect of Fasudil on Remyelination Following Cuprizone-induced Demyelination. CNS Neurosci. Ther. 26 (1), 76-89. doi:10.1111/cns.13154

Wittling, M. C., Cahalan, S. R., Levenson, E. A., and Rabin, R. L. (2020). Shared and Unique Features of Human Interferon-Beta and Interferon-Alpha Subtypes. Front. Immunol. 11, 605673. doi:10.3389/fimmu.2020.605673

Wolinsky, J. S., Narayana, P. A., Nelson, F., Datta, S., O'Connor, P., Confavreux, C., et al. (2013). Magnetic Resonance Imaging Outcomes from a Phase Iii Trial of 
Teriflunomide. Mult. Scler. 19 (10), 1310-1319. doi:10.1177/ 1352458513475723

Xiao, Y., Huang, J., Luo, H., and Wang, J. (2014). Mycophenolate Mofetil for Relapsing-Remitting Multiple Sclerosis. Cochrane Database Syst. Rev. (2), CD010242. doi:10.1002/14651858.CD010242.pub2

Yamout, B. I., and Alroughani, R. (2018). Multiple Sclerosis. Semin. Neurol. 38 (2), 212-225. doi:10.1055/s-0038-1649502

Yang, C., Hao, Z., Zhang, L., Zeng, L., and Wen, J. (2015). Sodium Channel Blockers for Neuroprotection in Multiple Sclerosis. Cochrane Database Syst. Rev. 10, CD010422. doi:10.1002/14651858.CD010422.pub2

Ye, N., Cruz, J., Peng, X., Ma, J., Zhang, A., and Cheng, X. (2021). Remyelination Is Enhanced by Astragalus Polysaccharides Through Inducing the Differentiation of Oligodendrocytes from Neural Stem Cells in Cuprizone Model of Demyelination. Brain Res. 1763, 147459. doi:10.1016/j.brainres.2021.147459

Yeung, M. S. Y., Djelloul, M., Steiner, E., Bernard, S., Salehpour, M., Possnert, G., et al. (2019). Dynamics of Oligodendrocyte Generation in Multiple Sclerosis. Nature 566 (7745), 538-542. doi:10.1038/s41586-018-0842-3

Yi, W., Schlüter, D., and Wang, X. (2019). Astrocytes in Multiple Sclerosis and Experimental Autoimmune Encephalomyelitis: Star-Shaped Cells Illuminating the Darkness of Cns Autoimmunity. Brain Behav. Immun. 80, 10-24. doi:10.1016/j.bbi.2019.05.029

Yin, L.-L., Lin, L.-L., Zhang, L., and Li, L. (2012). Epimedium Flavonoids Ameliorate Experimental Autoimmune Encephalomyelitis in Rats by Modulating Neuroinflammatory and Neurotrophic Responses. Neuropharmacology 63 (5), 851-862. doi:10.1016/j.neuropharm.2012.06.025

Yin, L., Chen, Y., Qu, Z., Zhang, L., Wang, Q., Zhang, Q., et al. (2014). Involvement of Jak/Stat Signaling in the Effect of Cornel Iridoid Glycoside on Experimental Autoimmune Encephalomyelitis Amelioration in Rats. J. Neuroimmunology 274 (1-2), 28-37. doi:10.1016/j.jneuroim.2014.06.022

Yu, L., Croze, E., Yamaguchi, K. D., Tran, T., Reder, A. T., Litvak, V., et al. (2015). Induction of a Unique Isoform of theNCOA7Oxidation Resistance Gene by Interferon $\beta$-1b. J. Interferon Cytokine Res. 35 (3), 186-199. doi:10.1089/ jir.2014.0115
Zettl, U. K., Hecker, M., Aktas, O., Wagner, T., and Rommer, P. S. (2018) Interferon $\beta$-1a and $\beta$-1b for Patients with Multiple Sclerosis: Updates to Current Knowledge. Expert Rev. Clin. Immunol. 14 (2), 137-153. doi:10.1080/1744666X.2018.1426462

Zhang, Y., Yin, L., Zheng, N., Zhang, L., Liu, J., Liang, W., et al. (2017). Icariin Enhances Remyelination Process After Acute Demyelination Induced by Cuprizone Exposure. Brain Res. Bull. 130, 180-187. doi:10.1016/ j.brainresbull.2017.01.025

Zhong, M., van der Walt, A., Campagna, M. P., Stankovich, J., Butzkueven, H., and Jokubaitis, V. (2020). The Pharmacogenetics of Rituximab: Potential Implications for Anti-cd20 Therapies in Multiple Sclerosis. Neurotherapeutics 17 (4), 1768-1784. doi:10.1007/s13311-020-00950-2

Zhou, Y., Leng, X., Luo, S., Su, Z., Luo, X., Guo, H., et al. (2016). Tolerogenic Dendritic Cells Generated with Tofacitinib Ameliorate Experimental Autoimmune Encephalomyelitis through Modulation of Th17/Treg Balance. J. Immunol. Res. 2016, 1-13. doi:10.1155/2016/50215372016

Zhovtis Ryerson, L., Li, X., Goldberg, J. D., Hoyt, T., Christensen, A., Metzger, R. R., et al. (2020). Pharmacodynamics of Natalizumab Extended Interval Dosing in Ms. Neurol. Neuroimmunol Neuroinflamm 7 (2), e672. doi:10.1212/ NXI.0000000000000672

Ziemssen, T. (2011). Symptom Management in Patients with Multiple Sclerosis. J. Neurol. Sci. 311 (Suppl. 1), S48-S52. doi:10.1016/S0022-510X(11)70009-0

Conflict of Interest: The authors declare that the research was conducted in the absence of any commercial or financial relationships that could be construed as a potential conflict of interest.

Copyright (c) $2021 \mathrm{Wei}, \mathrm{Ma}$, Li and Zhang. This is an open-access article distributed under the terms of the Creative Commons Attribution License (CC BY). The use, distribution or reproduction in other forums is permitted, provided the original author(s) and the copyright owner(s) are credited and that the original publication in this journal is cited, in accordance with accepted academic practice. No use, distribution or reproduction is permitted which does not comply with these terms. 